\title{
Effect of sustained release terbutaline on symptoms and sleep quality in patients with nocturnal asthma
}

\author{
I C STEWART, G B RHIND, J T POWER, D C FLENLEY, N J DOUGLAS \\ From the Department of Respiratory Medicine and Rayne Laboratory, University of Edinburgh, City Hospital, \\ Edinburgh
}

ABSTRACT The effect of an oral sustained release $\beta_{2}$ agonist on symptoms, sleep quality, and peak flow rates has been studied in nine patients with nocturnal asthma. Patients received oral terbutaline $7.5 \mathrm{mg}$ twice daily or placebo for seven days in a double blind crossover study and spent the last two nights of each limb in a sleep laboratory. Oral terbutaline improved morning peak flow (259v $\left.2131 \mathrm{~min}^{-1}\right)$ and decreased nocturnal inhaler usage (1.3v 1.9) with no alteration in sleep quality as assessed electroencephalographically. The study shows that oral sustained release terbutaline can be useful in the treatment of nocturnal asthma without impairment of sleep quality.

Many patients with asthma are troubled by cough and wheeze at night and are found to have a "morning dip" in forced expiratory flow. ${ }^{1}$ These nocturnal symptoms are associated with poorer sleep quality ${ }^{2} 3$ and worse hypoxia during sleep ${ }^{3}$ than is found in age matched normal subjects. Nocturnal asthma may be difficult to treat. ${ }^{4}$ When the combination of inhaled bronchodilators and inhaled prophylactic agents do not control symptoms, sustained release oral bronchodilators in the form of theophylline or $\beta_{2}$ agonists are frequently used.

We have recently shown that while oral theophyllines are effective overnight bronchodilators they may impair sleep quality. ${ }^{5}$ We have now studied the effect of an oral sustained release $\beta_{2}$ agonist on peak expiratory flow, arterial oxygen saturation, and sleep quality in patients with nocturnal asthma.

\section{Methods}

We studied nine patients with stable asthma who had troublesome nocturnal wheeze or cough, or both, (table 1). Each had a greater than $20 \%$ increase in $\mathrm{FEV}_{1}$ after inhalation of $200 \mu \mathrm{g}$ of terbutaline. Five were atopic with positive responses to skin tests with grass pollens, dust, or animal dander. None had had an exacerbation of asthma for at least six weeks before the study. Antihistamines, hypnotics, and ketotifen were discontinued at least four weeks before

Address for correspondence: Dr N J Douglas, Department of Respiratory Medicine, City Hospital, Edinburgh EH10 5SB. (Reprints will not be available).

Accepted I April 1987 the study, and the three patients who had received either oral theophylline or oral $\beta_{2}$ agonists previously discontinued the drugs at least three weeks before the study. Six patients were receiving oral prednisolone (5-10 mg daily), and eight of the nine patients were inhaling steroids $(400-800 \mu \mathrm{g}$ betamethasone or beclomethasone a day). All were inhaling $\beta_{2}$ agonists, which were withheld for at least six hours before the studies in the sleep laboratory. No subject was taking sodium cromoglycate and none smoked.

The nine patients received oral terbutaline (Bricanyl, South Africa) $7.5 \mathrm{mg}$ twice daily or placebo for seven days in a double blind crossover study. There was a washout period of at least 24 hours (no longer than 10 days) between the two limbs of the study. Symptoms and peak flow (PEF) recorded during the first 48 hours of each limb of the study were excluded from subsequent analyses, to avoid any carry over

Table 1 Details of the subjects

\begin{tabular}{lllll}
\hline $\begin{array}{l}\text { Patient } \\
\text { No }\end{array}$ & Age $(y)$ & $\begin{array}{l}F E V_{1} \\
(l)\end{array}$ & $\begin{array}{l}\text { Vital } \\
\text { capacity } \\
(l)\end{array}$ & Treatment \\
\hline 1 & 56 & $2 \cdot 0$ & $3 \cdot 8$ & B, S, T \\
2 & 59 & $2 \cdot 0$ & $4 \cdot 9$ & B, S, P (5) \\
3 & 61 & $2 \cdot 0$ & $3 \cdot 3$ & B, S, P (10) \\
4 & 54 & $1 \cdot 5$ & $2 \cdot 4$ & B, S, T \\
5 & 65 & 1.9 & $2 \cdot 4$ & B, S, I, P (5), k \\
6 & 68 & $1 \cdot 7$ & $3 \cdot 8$ & B, S, P (7.5), t \\
7 & 59 & $1 \cdot 4$ & $2 \cdot 3$ & B, I, P (5) \\
8 & 32 & $3 \cdot 0$ & $4 \cdot 5$ & B, S \\
9 & 51 & 1.9 & 3.9 & B, S, I, P (10) \\
\hline
\end{tabular}

B-inhaled $\beta_{2}$ agonist; $\mathrm{S}$-inhaled steroid; $\mathrm{T}$-oral theophylline; $\mathrm{P}$-oral prednisolone, with daily dose in $\mathrm{mg}$ in parentheses; $\mathrm{I}$-inhaled ipratropium bromide; $\mathrm{k}$ - ketotifen; $\mathrm{t}-$ terbutaline. 
effects and to allow terbutaline concentrations to stabilise. Throughout the study the patients recorded on a diary card each day their PEF four times a day, symptom score $(0=$ no symptoms, $3=$ severe symptoms), inhaler usage, and number of awakenings with cough or wheeze. On the last two nights of each limb of the study the patients slept in a soundproof laboratory; the first night was for acclimatisation and only the sleep data from the second night were analysed. Arterial oxygen saturation $\left(\mathrm{SaO}_{2}\right)$ was measured by the Hewlett Packard ear oximeter ${ }^{6}$ and sleep stage was determined by standard criteria, ${ }^{7}$ our usual electrode placement ${ }^{3}$ being used. An electroencephalographic awakening was said to occur when wakefulness was the dominant stage in a 20 second epoch. PEF was measured immediately before the subjects went to bed and immediately they awoke.

Plasma terbutaline concentrations were assayed by high pressure liquid chromatography ${ }^{8}$ and by gasliquid chromatography and mass spectrometry ${ }^{9}$ from venous blood drawn at $10 \mathrm{pm}$ and $7 \mathrm{am}$ on the night of the sleep studies. The assays were performed by Draco (Lund, Sweden).

The significance of changes was assessed by Student's paired $t$ test, the Bonferroni correction for multiple comparisons being used where applicable. ${ }^{10}$ Results are given as means with standard errors in parentheses.

\section{Results}

TERBUTALINE LEVELS

Terbutaline (molwt 548) was undetectable in all plasma samples from the placebo nights. On the study nights when the patients were taking active drug, plasma terbutaline ranged from $2 \cdot 8$ to $28 \cdot 1 \mathrm{nmol} / 1$ with no significant difference between concentrations at $10 \mathrm{pm}(14 \cdot 2(2 \cdot 7) \mathrm{nmol} / \mathrm{l})$ and $7 \mathrm{am}(14 \cdot 7(2 \cdot 7)$ $\mathrm{nmol} / \mathrm{l})$.

\section{PEAK FLOW RATES}

During the three nights at home neither the presleep

Table 2 Mean peak expiratory flow rates (PEF; standard errors in parentheses) of the subjects when they awoke (am) and immediately before the went to bed ( pm) for the three nights at home and the wo nights in the sleep laboratory while they took placebo and terbutaline

\begin{tabular}{|c|c|c|c|c|}
\hline & \multicolumn{4}{|c|}{ Peak How $(/ \min 1)$} \\
\hline & \multicolumn{2}{|l|}{ Ilome } & \multicolumn{2}{|c|}{ Sleep laboratory } \\
\hline & $a m$ & $p m$ & $a m$ & $p m$ \\
\hline $\begin{array}{l}\text { Placebo } \\
\text { Terbutaline }\end{array}$ & $\begin{array}{l}235(17) \\
247(19)\end{array}$ & $\begin{array}{l}287(19)^{*} \\
285(26)\end{array}$ & $\begin{array}{l}213(22) \\
259(19) \dagger\end{array}$ & $\begin{array}{l}301(23)^{*} \\
287(24)\end{array}$ \\
\hline
\end{tabular}

nor the early morning PEF values differe significantly between the terbutaline and placebo days (table 2; $\mathrm{p}>0.2$ ). The overnight fall in PEF was significant after placebo $\left(521 \mathrm{~min}^{-1}\right)$, whereas the fa after terbutaline was not significant $\left(381 \mathrm{~min}^{-1}\right)$.

For the nights spent in the laboratory, PEF before sleep did not differ significantly between the terbutaline and placebo periods (table $2 ; p>0.5$ ) but II was significantly higher in the morning during the ter butaline period ( $p<0.05$; fig 1$)$. On the laborator nights the patients bronchoconstricted overnight wit a fall in PEF of $881 / \mathrm{min}(\mathrm{p}<0.02)$ compared with fall of $281 \mathrm{~min}^{-1}$ on terbutaline $(\mathrm{p}>0 \cdot 3)$.

\section{SYMPTOMS}

During the three days at home subjects used less inhaler at night while taking terbutaline than whife taking placebo $(1.3$ (SEM 0.2) $v 1.9(0.4)$ puffs/nigh $\overrightarrow{0}$ $\mathrm{p}<0.02)$ and there was a trend towards their being woken less often by cough or wheeze when takin terbutaline $(1.0(0.2) v 1.4(0.4)$ awakenings/night; 0.9 $>p>0.05)$. There was no difference in nocturnat $(1.2(0.3) \vee 1.5(0.2) ; \mathrm{p}>0.3)$ or daytime symptoms score $(1.6(0.2) \vee 1.8(0.2) ; \mathrm{p}>0.3)$. One patient reported minor muscle aches while taking terbutaline at the time of the laboratory studies but none reported tremor.

SLEEP QUALITY

In the sleep laboratory there was no significan

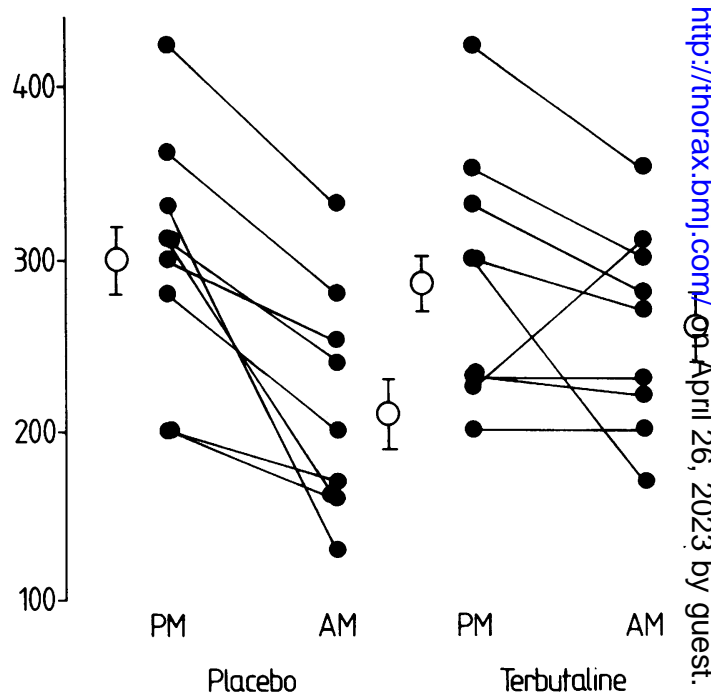

Fig 1 Peak expiratory flow (PEF) measured in the sleep laboratory before and after sleep in nine patients taking placebo and oral terbutaline. Open symbols represent mean $\triangle$ and standard errors. Morning peak flow rates were significantly higher while they took terbutaline than while they took placebo. 


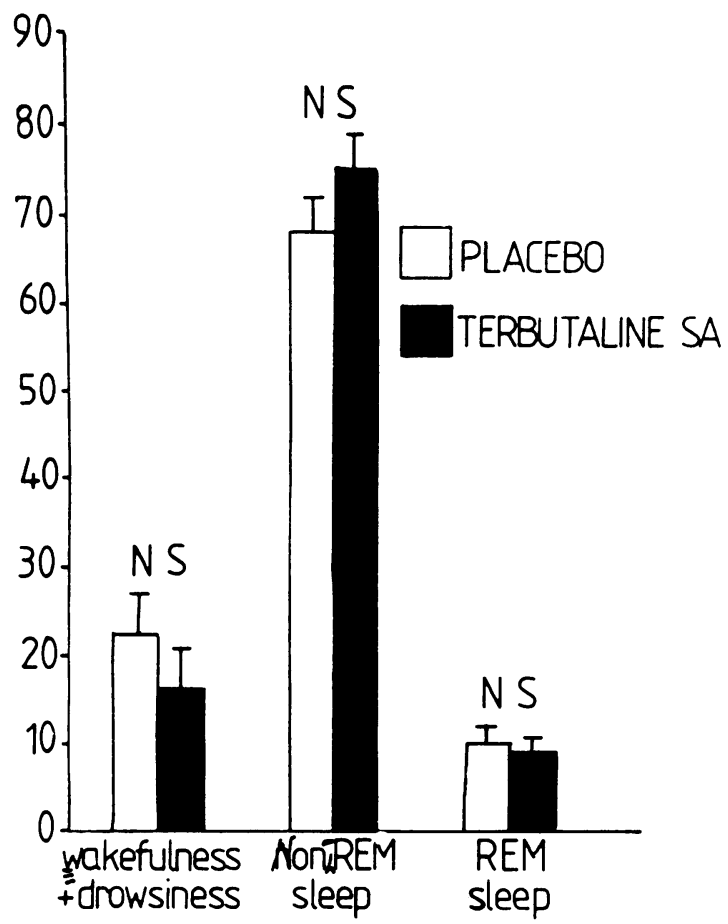

Fig 2 Sleep quality in the nine patients while they took placebo ( $\square$ ) and terbutaline ( $\square$ ), indicating the percentage of the sleep period spent in wakefulness and drowsiness, non-rapid eye movement (non-REM-stages 2, 3, and 4) sleep, and REM sleep. Terbutaline did not significantly change sleep quality.

difference in the time spent in bed (terbutaline 385 (SEM 12) $v$ placebo 391 (8) $\mathrm{min} ; \mathrm{p}>0 \cdot 5$ ); total sleep time $323(21) v 306(25) ; \mathrm{p}>0.5)$ or in the time spent in each sleep stage (fig 2). There was no difference in the number of EEG documented awakenings during the night during the terbutaline (14 (3)) or the placebo period (20(3); $\mathrm{p}>0 \cdot 1)$.

\section{OXYGENATION}

There was no significant difference in $\mathrm{SaO}_{2}$ while subjects were awake (terbutaline 94.7\% (SEM 0.3\%) $v$ placebo $95.2 \%(0.2 \%) ; 0.1>p>0.05)$, in the lowest $\mathrm{SaO}_{2}$ value recorded during the night $(85.7 \%(0 \cdot 1 \%) v$ $85.8 \%(2.0 \%) ; \mathrm{p}>0.5)$ or in the number of $4 \%$ desaturations per night $(3.3(0.6) v 2 \cdot 8(1 \cdot 1) ; \mathrm{p}>0 \cdot 3)$.

\section{Discussion}

This study confirms that oral sustained release terbutaline can improve morning peak flow rates in patients who have troublesome nocturnal asthma that has not responded to inhaled $\beta_{2}$ agonists and inhaled prophylactic agents. Terbutaline did not impair sleep quality, and indeed there was a trend towards a decreased number of awakenings reported while patients were taking oral terbutaline.

Nocturnal asthma is ill understood ${ }^{4}$ and often difficult to treat. This study confirms previous findings ${ }^{11}$ showing that oral slow release $\beta_{2}$ agonists can improve PEF and decrease nocturnal inhaler usage in patients with nocturnal asthma. We did not, however, find the clear reduction in nocturnal symptoms reported by others. ${ }^{12}$

Theophyllines and $\beta_{2}$ agonists are stimulants of the central nervous system and potentially therefore could interfere with sleep. ${ }^{1314}$ Long acting theophyllines have been shown to impair sleep quality, as assessed by EEG recording, in patients with nocturnal asthma ${ }^{5}$ and chronic bronchitis and emphysema. ${ }^{15}$ The current study shows that oral $\beta_{2}$ agonists improve nocturnal asthma without disturbing sleep, and indeed the trend was towards improved sleep quality while patients were taking terbutaline.

No detailed information is available on the therapeutic range for terbutaline. The plasma concentrations achieved in this study, however, are in the range quoted by Astra Pharmaceuticals and by others ${ }^{12}$ as being therapeutic.

This study therefore confirms that oral sustained release terbutaline can be useful in treating nocturnal asthma. The lack of deleterious effect on sleep quality suggests that this may be the oral sustained release agent of choice in those patients who obtain symptomatic relief without developing side effects. Nevertheless, this treatment is still not ideal as it did not produce great changes in peak flow, did not prevent awakenings with wheeze or use of inhalers at night, did not improve nocturnal symptoms, and did not reduce nocturnal hypoxaemia.

We thank Staff Nurse Carol Hoy for technical assistance and Astra (UK Ltd) for financial support.

\section{References}

1 Turner-Warwick M. On observing patterns of air flow obstruction in chronic asthma. $\mathrm{Br} J$ Dis Chest 1977;71:73-86.

2 Montplaisir J, Walsh J, Malo JL. Nocturnal asthma: features of attacks, sleep and breathing patterns. $\mathrm{Am}$ Rev Respir Dis 1982;125:18-22.

3 Catterall JR, Douglas NJ, Calverley PMA, et al. Irregular breathing and hypoxaemia during sleep in chronic stable asthma. Lancet 1982;i:301-4.

4 Douglas NJ. Asthma at night. Clin Chest Med 1985;6:663-74.

5 Rhind GB, Connaughton JJ, McFie J, Douglas NJ, Flenley DC. Sustained release choline theophyllinate in nocturnal asthma. $\mathrm{Br}$ Med J 1985;291:1605-7. 
6 Douglas NJ, Brash HM, Wraith PK, et al. Accuracy, sensitivity to carboxyhaemoglobin and speed of response of the Hewlett Packard 47201A ear oximeter. Am Rev Respir Dis 1979;119:311-3.

7 Rechtschaffen A, Kales A. Manual of standardised terminology, techniques and scoring system for sleep stage of human subjects. Washington DC: Public Health Service, US Government Printing Office, 1968.

8 Bergquist S, Edholm L-E. Quantitative analysis of terbutaline (Bricanyl R) in human plasma with liquid chromatography and electrochemical detection using on-line enrichment. J Liq Chromatogr 1983;6:559-74.

9 Leferink JG, Wagemaker-Engels I, Maes RAA, et al. Quantitative analysis of terbutaline in serum and urine at therapeutic levels using gas chromatography-mass spectrometry. J Chromatogr 1977;143:299-305.

10 Miller RG. Simultaneous statistical inference. New York: Springer-Verlag, 1981:62.

11 Fairfax AJ, McNabb WR, Davies HJ, Spiro SG. Slow release oral salbutamol and aminophylline i nocturnal asthma: relation of overnight changes im lung function and plasma drug levels. Thora 1978;35:526-30.

12 Koeter GH, Postma DS, Keyzer JJ, Meurs H. The effeç of oral slow-release terbutaline on early morning dy pnoea. Eur J Clin Pharmacol 1985;28:159-62.

13 Weiner N. Norepinephrine, epinephrine and thfe sympathomimetic-amines. In: Goodman LS, Gillma $\overrightarrow{\text { D }}$ A, eds. The pharmacological basis of therapeutics. 6tits ed. New York: McMillan, 1980:149.

14 Rall TW. Central nervous system stimulants-the xans

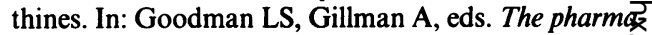
cological basis of therapeutics. 6th ed. New Yoris McMillan, 1980:593-4.

15 Fleetham JA, Fera T, Edgill GM, Jamal K. The effect $\vec{\phi}$ theophylline therapy on sleep disorders in chronig obstructive pulmonary disease patients. Am ReN Respir Dis 1983;127(suppl):85. 